\title{
A Fragilidade do Capital Social como Fator Prejudicial ao Desenvolvimento do Turismo na Quarta Colônia - RS
}

\author{
La Fragilidad del Capital Social como Factor Perjudicial al Desarrollo \\ del Turismo en la Cuarta Colonia - RS
}
The Fragility of Social Capital as a Prejudicial Factor to the Development of Tourism in the Fourth Colony - RS

\section{Adriana Pisoni da Silva ${ }^{1}$ José Marcos Froehlich²}

\begin{abstract}
Resumo
O presente artigo tem como objetivo apresentar reflexões sobre os obstáculos que tem dificultado a consolidação do turismo na Quarta Colônia, território na região central do Rio Grande do Sul, Brasil. O pressuposto que guiou a investigação baseia-se em que estes obstáculos estão em boa medida relacionados à debilidade do capital social no território. $\mathrm{O}$ embasamento teórico atendeu principalmente às noções de: a) Desenvolvimento Territorial, b) Capital Social e c) Turismo. Para a análise da constituição do capital social buscou-se evidenciar a recorrência das categorias teóricas operacionais: Relações de Confiança, Cooperação e Ação Coletiva. A opção metodológica foi a pesquisa qualitativa, com lócus empírico no território de Santa Maria - Quarta Colônia, tendo como recorte o período temporal a partir do ano de 1995. A pesquisa de campo, contemplando as etapas de observações e aplicação de entrevistas semiestruturadas com os atores locais, foi realizada no período de 2013 a 2014. Em termos de resultados, inferiu-se que são frágeis as relações entre os atores, quase inexistentes as ações coletivas no âmbito do turismo, apresentando relatos individualistas e de competição entre eles, o que tem tornado débil o capital social no território. Conclui-se que a fragilidade do capital social é um dos principais fatores que dificultam a superação dos obstáculos para maior consolidação do turismo e de suas repercussões no desenvolvimento do território.
\end{abstract}

Palavras-Chave: Desenvolvimento Territorial; Turismo; Capital Social; Confiança.

\section{Resumen}

El presente artículo tiene como objetivo presentar reflexiones sobre los obstáculos que ha difícultado la consolidación del turismo en la Cuarta Colonia, territorio en la región central de Rio Grande do Sul, Brasil. El supuesto que guió la investigación se basa en que estos obstáculos están en buena medida relacionados con la debilidad del capital social en el territorio. La base teórica atendió principalmente a las nociones de: a) Desarrollo Territorial, b) Capital Social y c) Turismo. Para el análisis de la constitución del capital social se buscó evidenciar la recurrencia de las siguientes categorías teóricas operativas: a) Relaciones de Confianza, b) Cooperación; c) Acción Colectiva. La opción metodológica fue la investigación cualitativa, con locus empírico en el eje Santa María - Cuarta Colonia, teniendo como recorte el período temporal a partir del año 1995. La investigación de campo, contemplando las etapas de observaciones y aplicación de entrevistas semiestructuradas con los actores se realizó en el período de 2013 a 2014. En términos de resultados, se infería que son frágiles las relaciones entre los actores, casi inexistentes las acciones colectivas en el ámbito del turismo, presentando relatos

\footnotetext{
${ }^{1}$ Doutora em Extensão Rural pela Universidade Federal de Santa Maria (UFSM); Mestra em Planejamento Urbano e Regional pela Universidade Federal do Rio Grande do Sul (UFRGS); Bacharel em Turismo pela Pontifícia Universidade Católica (PUC/RS). Professora do Curso Superior de Tecnologia em Gestão de Turismo da Universidade Federal do Pampa (UNIPAMPA), adrianapisoni@gmail.com

${ }^{2}$ Pós-Doutor em Antropologia Social pela Universidad de Sevilla (Espanha); Doutor em Ciências Sociais pela UFRRJ; Mestre em Sociologia pela UFRGS e Graduação em Agronomia pela UFSM. Professor no Departamento e nos PPGs em Extensão Rural e em Ciências Sociais da Universidade Federal de Santa Maria (UFSM). E-mail: jmarcos.froehlich@ gmail.com.
} 
individualistas y de competencia entre ellos, lo que tiene ha debilitado el capital social en el territorio. Se concluye que la fragilidad del capital social es uno de los principales factores que dificultan la superación de los obstáculos para una mayor consolidación del turismo y de sus repercusiones en el desarrollo del território.

Palabras claves: Desarrollo Territorial; Turismo; Capital Social; Confianza.

\begin{abstract}
This study aims to present reflections on the obstacles that have hampered the consolidation of tourism in the Quarta Colônia, territory in the central region of Rio Grande do Sul, Brazil. The assumption that guided the research is based on the fact that these obstacles are largely related to the weakness of social capital in the territory. The theoretical background was mainly based on the notions of: a) Territorial Development, b) Social Capital and c) Tourism. For the analysis of the constitution of the social capital, the recurrence of the following theoretical operational categories was evidenced: a) Confidence Relationships, b) Cooperation; C) Collective action. The methodological option was the qualitative research, with empirical locus in the Santa Maria - Quarta Colônia, from the year of 1995. The field research, contemplating the stages of observations and application of semi-structured interviews with the local actors, was made from 2013 to 2014. In terms of results, it was inferred that the relations between the actors are fragile, the collective actions in the field of tourism was almost nonexistent, presenting individualistic and competition reports among them, which has made the social capital in the territory weak. It was concluded that the fragility of social capital is one of the main factors that make difficult to overcome the obstacles to greater consolidation of tourism and its repercussions in the development of the territory.
\end{abstract}

Keywords: Territorial Development; Tourism; Social Capital; Confidence.

\title{
1. Introdução
}

A pesquisa sobre o turismo na perspectiva do desenvolvimento territorial vem ganhando cada vez mais destaque no contexto nacional e internacional. Nas últimas décadas, há uma nova configuração na ocupação do meio rural, avançando para além da produção agropecuária, onde estratégias de desenvolvimento estão associadas também à conservação ambiental e paisagística das regiões interioranas, além da capacidade de organização, fazendo destes atributos as bases de geração de trabalho e renda. O Instituto de Desenvolvimento do Turismo Rural (IDESTUR, 2011) reconhece que a atividade turística no espaço rural brasileiro começou a se fortalecer aproximadamente a partir dos anos de 1980, apresentando diversas modalidades e denominações: turismo rural, turismo de interior, turismo alternativo, turismo verde, turismo de campo, agroturismo, entre outros.

Assim, atentos ao cenário do turismo na Região Central do Rio Grande do Sul, o estado mais meridional do Brasil, opta-se pelo recorte empírico de análise desta pesquisa o território da Quarta Colônia, principalmente no eixo de conexão entre o principal município, Santa Maria, e a Quarta Colônia, instigados a analisar a solidez da perspectiva do turismo enquanto uma estratégia de desenvolvimento para tal território. O território Quarta Colônia está situado no centro do Rio Grande do Sul e é formada por nove municípios, considerando a delimitação abarcada pelo Consórcio de Desenvolvimento Sustentável (CONDESUS) da 
Quarta Colônia, contemplando os municípios de Agudo, Dona Francisca, Faxinal do Soturno, Ivorá, Nova Palma, Restinga Sêca, Silveira Martins, São João do Polêsine e Pinhal Grande, totalizando uma população, conforme o IBGE (2010), de 60.697 habitantes.

Tendo em vista as recorrentes iniciativas e estudos que, ao longo das últimas décadas, em especial nesta última, com a institucionalização de roteiros e rotas turísticas: Roteiros Turísticos Integrados da Quarta Colônia (2002) e Rota Turística e Gastronômica Santa Maria - Silveira Martins (2005) e reconhecido o potencial do turismo na Quarta Colônia, mas que tem encontrado dificuldades em consolidar-se e realizar este suposto potencial, a questão que se coloca é avaliar quais seriam os motivos que geram a dificuldade em avançar no desenvolvimento do turismo neste território? Objetiva-se argumentar neste artigo que as dificuldades em realizar o potencial e fazer avançar e consolidar o desenvolvimento do turismo na Quarta Colônia decorre da fragilidade do capital social que acarreta obstáculos para a cooperação, o trabalho em rede e, por conseguinte, para a sinergia de ações entre os atores envolvidos neste processo, examinando a recorrência ou não de laços de confiança, relações de cooperação, ações coletivas e inovações estabelecidas entre os atores envolvidos com o turismo na Quarta Colônia.

A pesquisa torna-se relevante no momento em que trata da proeminente relação entre o turismo e o desenvolvimento territorial em municípios rurais, considerando a mobilidade do território e a contínua apropriação da lógica da multifuncionalidade do meio rural. A Quarta Colônia é um território rural privilegiado quanto à preservação da paisagem e das identidades culturais, tornando-se atrativa principalmente para o público regional, gerando um fluxo de turistas, com mais expressividade aos finais de semana, os quais buscam desfrutar das atividades turísticas oferecidas neste cenário rural (FROEHLICH, 2012).

Quanto ao enfoque metodológico, opta-se pela pesquisa qualitativa, de caráter descritivo e interpretativo (MINAYO, 1994), com o propósito de analisar as relações decorrentes da estrutura sistêmica do turismo em territórios rurais com a intersecção da temática do capital social, noção central na promoção do desenvolvimento territorial. Os procedimentos metodológicos utilizados foram a pesquisa bibliográfica, centrada na temática do desenvolvimento territorial e capital social, a pesquisa documental, a pesquisa de campo, valendo-se das técnicas de observação livre e entrevista. A interpretação dos dados e a reflexão empírica sobre a problemática foi possível por meio da combinação das técnicas de pesquisa na constituição da abordagem qualitativa deste estudo. Para análise dos dados coletados, adotou-se a técnica da triangulação das informações coletadas, contemplando a concepção de Triviños (1987, p.138): “a técnica da triangulação tem por objetivo básico 
abranger a máxima amplitude na descrição, explicação e compreensão do foco em estudo [...]". Refletir, triangular os conhecimentos acerca do aporte teórico, dos dados coletados na pesquisa de campo, no que diz respeito as Relações de Confiança, Cooperação e Ação Coletiva.

Foram aplicados roteiros de entrevistas com 25 informantes de distintos grupos focais, entre eles representantes do terceiro setor de associações, fóruns e consórcios, gestores públicos municipais e empresários de pequenos negócios de serviços turísticos, realizadas entre os meses de novembro de 2013 e abril de 2014. Os informantes não são identificados nominalmente, atribui-se letras aleatórias para a apresentação dos resultados de suas falas. Para a elaboração do roteiro do questionário toma-se como referência o conjunto de indicadores adotados pelo Banco Mundial (WOLD BANK, 2004), no seu Questionário Integrado para Medir Capital Social (QIMCS).

$\mathrm{Na}$ próxima sessão traz-se uma reflexão sobre a temática do desenvolvimento territorial e capital social, apresentando conceitos e definições, com o intuito de fortalecer a análise das inquietações sobre o avanço do desenvolvimento do turismo na microrregião da Quarta Colônia de Imigração Italiana do Rio Grande do Sul.

\section{Desenvolvimento territorial e capital social}

A discussão acerca de território começa com as acepções do termo, originário do latim territorium, adjetivo derivado de territorialis que significa "pedaço de terra apropriada". Este sentido era-lhe atribuído antes do século XVIII. Nos anos vinte, do século XX, os termos território e territorialidade transferem-se do domínio político-administrativo para o da etologia, adquirindo status de conceito científico, deixando de ser uma qualidade jurídica para transformar-se num sistema de comportamento.

No campo da etologia, o território está associado à demarcação e dominação de um lugar, à extensão e limites, enquanto territorialidade é definida como a conduta de um organismo para tomar posse de seu território. Em geografia, Milton Santos refere-se ao território como sendo "[...] o chão da população, isto é, sua identidade, o fato e o sentimento de pertencer àquilo que nos pertence. O território é a base do trabalho, da residência, das trocas materiais e espirituais e da vida, sobre os quais ele influi" (SANTOS, 2000, p. 96).

O território possui, antes de tudo, um tecido social, com relações de bases históricas e políticas que vão além da análise econômica. À dimensão territorial do desenvolvimento somam-se as dimensões temporais, como os ciclos econômicos e setoriais (ABRAMOVAY, 
2001; 2003). Segundo Haesbaert (2006), os conceitos de território variam de área para área e são delimitados conforme o enfoque de determinada perspectiva. Enquanto os geógrafos enfatizam a materialidade do território, a ciência política enfatiza as relações de poder, ligada à concepção de Estado; a economia adota a noção de espaço à de território; a antropologia destaca território como forma simbólica; a sociologia enfoca-o a partir de sua intervenção nas relações sociais e a psicologia incorpora-o no debate sobre a construção da subjetividade ou da identidade pessoal.

O território está relacionado com as raízes do local, fato este que, para o turismo, é imprescindível, ocupando-se da dimensão espacial na delimitação do produto turístico que é fixo e, consequentemente, exige o deslocamento do consumidor até ele. Para Cruz (2000), a fixidez do produto turístico constitui um dos vetores que orientam a organização espacial demandada pela atividade, enquanto Beni traz a seguinte consideração:

O território é um agente de transformação, não mero suporte dos recursos e atividades econômicas, pois existe interação entre as empresas e os demais atores, que se organizam para desenvolver a economia e a sociedade. $\mathrm{O}$ ponto de partida para uma comunidade territorial está no conjunto de recursos econômicos, humanos, institucionais e culturais formadores de seu potencial de desenvolvimento. (BENI, 2006, p. 36).

A constituição de territorialidades está embasada não apenas na percepção geográfica de espaço, mas também no seu tecido social, nas relações culturais, sociais, políticas e econômicas que dinamizam os ambientes e valoram seus saberes, práticas e sua história (ABRAMOVAY, 2003). Ademais, estes processos de valorização das regiões rurais, por suas características peculiares, denotam dimensões prósperas atualmente, contestando os dizeres históricos de extinção do rural e superando o significado de atraso que lhe foi associado nas visões da modernização conservadora, construindo novos sentidos para o desenvolvimento contemporâneo e novos papéis para os territórios rurais (FROEHLICH, 2002).

Para Favareto (2006), foi na primeira década dos anos 2000 que iniciou uma reavaliação do significado do desenvolvimento rural, compondo a pauta dos debates sobre as relações entre o rural e o urbano e sobre as abordagens das dinâmicas territoriais nos processos de desenvolvimento. Para o autor, na transição para o século XXI, houve avanços teóricos significativos no campo da temática da agricultura familiar; todavia, tal densidade acadêmica ainda não se afirmou no campo da abordagem territorial. Favareto (2006) entende que a abordagem territorial emerge num contexto social e histórico específico, revelando-se tanto uma categoria empírica, como uma visão cognitiva, formulada para dar conta da dinâmica emanada desta nova situação, demonstrando que tal abordagem territorial implica, sobretudo, o dimensionamento de uma escala específica de processos de desenvolvimento, 
onde, ao invés de uma análise dicotômica do urbano e do rural, torna-se necessário um enfoque relacional, que envolva os dois polos a partir do entendimento de suas relações de oposição e de complementaridade.

Na visão de Favareto (2006), em geral, são três os fatores principais que contribuem para a ocorrência de bons indicadores de desenvolvimento territorial: o aproveitamento do dinamismo gerado a partir da vitalidade dos espaços urbanos próximos; a incidência de fortes políticas sociais, com destaque para aquelas que implicam a transferência de fundos públicos e um dinamismo próprio de determinados espaços rurais. E, ainda, um quarto fator seria a presença de instituições locais que forneçam a coesão territorial e o aproveitamento dos recursos locais. Sendo assim, para Favareto (2006) a passagem do compromisso setorial ao territorial nas instituições e nas políticas para o desenvolvimento rural ainda é incompleta, sendo uma espécie de "inovação por adição" no vocabulário, no discurso e nas políticas de órgãos governamentais e de agentes sociais, sem, ainda, um correspondente em termos de mudança institucional e consolidação acadêmica.

Enquanto para Abramovay (2003), o planejamento contemporâneo ocupa-se de uma dimensão mais territorial que setorial, tendo como preocupação elementar a diversificação das fontes de geração de ocupação e renda, sobretudo, naquelas localidades que não são diretamente beneficiadas por processos espetaculares de inovação técnica. O desafio do planejamento territorial consiste em passar, de uma lógica federativa e de dependência das localidades em reivindicações aos poderes federais, para uma forma propositiva de racionalidade de projetos, nos quais uma região afirma sua identidade, suas ambições e suas capacidades de construir o futuro.

Para que esta nova lógica tenha êxito é necessário que se considere o capital social como um elemento essencial, sendo assim, os projetos locais e regionais serão instrumentos de coesão e participação mútua entre os atores em prol do desenvolvimento territorial. A noção de capital social vem ocupando um espaço de relevância nas últimas décadas no campo teórico que aborda o desenvolvimento. Destacam-se três teóricos importantes nos estudos relacionados à noção de Capital Social: Bourdieu (1985), Coleman (1990) e Putnam (2000).

Para Bourdieu (1985, p. 243), o capital social é "agregado de recursos reais ou potenciais que estão ligados à participação em uma rede durável de relações mais ou menos institucionalizadas de mútua familiaridade e reconhecimento".

As pesquisas de Coleman relatam o papel do capital social no crescimento do capital humano e as relações entre alcance educacional e desigualdade social, definindo capital social como "os recursos sócio estruturais que constituem um ativo de capital para o indivíduo e 
facilitam certas ações de indivíduos que estão dentro dessa estrutura" (COLEMAN, 1990, p. $312)$.

Coleman define três aspectos na constituição do capital social, o primeiro deles é o nível de confiança e a real extensão das obrigações existentes em um ambiente social, ou seja, quanto as pessoas confiam umas nas outras e como essa confiança é exercida pela aceitação mútua de obrigações, tem-se o capital social; o segundo aspecto diz respeito aos canais de trocas de informações e ideias; e o terceiro refere-se quando há normas e sanções que encorajam os indivíduos a trabalharem por um bem comum.

De acordo com Mueller (2007), a literatura é controversa quanto às possibilidades de criar ou incrementar capital social onde ele inexista e prevaleça a desconfiança generalizada. Neste aspecto, recebem recorrentes críticas os trabalhos de Putnam, em virtude da ênfase que dá a um determinismo cultural, o que significaria a impossibilidade de haver mudanças nos hábitos sociais em períodos de tempo relativamente curtos. Isto acarretaria dificuldade de gerar ou incrementar capital social em inúmeros territórios, aonde não haja tal tradição de engajamento cívico, o que, por sua vez, representaria sérios empecilhos ao próprio desenvolvimento.

Sendo assim, haveria sociedades onde prevaleceria um círculo virtuoso de existência de capital social e desenvolvimento, ao passo que, em outras, o cenário seria o inverso. No entanto, apesar deste caráter de determinismo cultural, Putnam não nega a possibilidade de o capital social ter alterações ao longo do tempo, pois afirma que "o capital social, à diferença de outras formas de capital, geralmente tem que ser gerado como subproduto de outras atividades sociais" (PUTNAM, 2000, p. 180).

Putnam definiu o capital social como as "características da organização social, como confiança, normas e sistemas, que contribuem para aumentar a eficiência da sociedade, facilitando as ações coordenadas" (PUTNAM, 2000, p. 117). Para o autor, "para a estabilidade política, para a boa governança e mesmo para o desenvolvimento econômico, o capital social pode ser mais importante até do que o capital físico e humano" (PUTNAM, 2000, p. 192). Seus estudos tratam sobre as diferenças regionais italianas, apontando a importância da comunidade cívica como elemento essencial para o bom desempenho institucional, econômico e político. Comunidade cívica, para o autor, é caracterizada "por cidadãos atuantes e imbuídos, por relações políticas igualitárias, por uma estrutura social firmada na confiança e na colaboração" (PUTNAM, 2000, p. 3031). Estes três aspectos estariam diretamente ligados ao engajamento cívico das pessoas de cada uma das regiões, sendo que o nível de engajamento é ligado à natureza do associativismo, se horizontal ou se 
vertical, sendo que esta natureza do associativismo seria de cunho cultural, historicamente constituída.

O associativismo horizontal é aglutinador de membros com o mesmo status e poder, já o vertical reuniria membros de forma assimétrica e hierárquica, significando a existência de laços de dominação e dependência, além da desconfiança generalizada e o fraco engajamento cívico. Porém, onde predomina o associativismo horizontal, pelo contrário, predominariam também a confiança e as normas de reciprocidade, juntamente com o maior engajamento cívico. Ou seja, onde há tradição de participação das pessoas em associações horizontais, sejam elas com fins políticos ou não, há mais confiança, mais cooperação, maior espírito democrático, prevalecendo os interesses coletivos em detrimento dos individuais, o que teria resultado em maior facilidade nas implementações dos projetos governamentais e, consequentemente, na obtenção de maiores benefícios para a população.

Putnam (2000) apresenta três formas de capital social: a primeira, que identifica capital social formal (associações, sindicatos, organizações, etc.) versus capital social informal (reuniões familiares ou de vizinhos); a segunda forma, capital social denso versus capital social escasso; e a terceira, capital social de ponte (que diz respeito a laços, que ligam pessoas com características demográficas diferentes) versus capital social de ligação (quando a base para a formação da rede é entre iguais, ou seja, entre indivíduos similares do ponto de vista de suas características demográficas).

A relação entre capital social e desenvolvimento pode ser feita à medida que a proximidade geográfica é um fator que pode facilitar o estabelecimento de laços de cooperação entre os empreendimentos produtivos, especialmente nas práticas endógenas, baseadas em arranjos e pequenas empresas. Contudo, deve-se considerar que, em determinadas regiões, as condições sociais estão dispersas ou pouco mobilizadas e não conseguem dar uma resposta no sentido de promover as "sinergias" para os setores produtivos. O interessante é conhecer de que forma as políticas locais agem sobre estes fatores e a quem cabe à governança do processo (ANÉSE, 2009).

\section{A falta de confiança, cooperação e ação coletiva entre os atores}

Tanto para Putnam (2000) quanto para Fukuyama (1996), a confiança é um elemento fundamental para a densidade de capital social. Para Fukuyama: "uma das lições mais importantes que podemos extrair de uma observação da vida econômica é a de que bem-estar de uma nação, bem como a sua capacidade de competir, são condicionados por uma única e sutil característica cultural: o nível de confiança inerente à sociedade” (1996, p.21). 
Os informantes entrevistados da microrregião da Quarta Colônia de Imigração Italiana/RS foram questionados quanto ao seu grau de confiança em relação à comunidade local, parceiros, prestadores de serviços e visitantes/turistas. Também responderam à questão se as pessoas da localidade ajudam umas às outras, entendendo que o fator confiança é um dos componentes que auxiliam na avaliação do potencial do capital social das localidades.

Quanto à existência de parceiros da empresa, a maioria dos empresários não identificou nenhum; somente alguns poucos entendem que os seus clientes são parceiros, porque ajudam na divulgação e promovem o empreendimento, recomendando e levando pessoas para conhecerem os estabelecimentos comerciais, e apenas um dos empresários citou o órgão público de turismo como um parceiro.

A gente até tem uma lista de clientes que nós chamamos de 'advogados' que eles nos defendem, né. [risos]; posso dizer que sim, por exemplo, o Melão da São Roque, jornais, é um parceiro legal. Ele vem sempre como cliente, quando tem algum evento importante, ele faz aqui. (Empresário AZ).

Basicamente, não. Tem a Secretaria de Turismo de Santa Maria, assim, mas tá, esse 2013 foi parado. Aquela integração que tinha no começo, até com a própria Secretaria de Turismo de Silveira Martins, trocavam, ou uma secretaria ajudava a outra com os eventos, faziam programações, 2013 não teve nada. (Empresário BY).

Para identificar o grau de confiança os empresários entrevistados foram questionados sobre a sua confiança com relação aos pares com a mesma etnia, entre os próprios empresários e as instituições, com relação ao governo local, com relação as instituições do sistema "S", com relação as universidades, e por fim, com os visitantes e turistas. Pergunta-se a nota que atribuíam a cada um destes grupos citados, numa escala de 1 a 7 , onde 1 quer dizer "confio muito pouco"; 2 "confio pouco"; 3 "nem pouco, nem muito"; 4 "confio muito"; 5 "confio totalmente"; 6 "desconheço" e 7 "não influencia na confiança", considerando a escala LICKERT (1932), dados estes apresentados na tabela 1.

Tabela 1 - Conceito do grau de confiança dos empresários por categorias e instituições

\begin{tabular}{|c|c|c|c|c|c|c|c|c|c|c|c|c|c|c|c|c|c|c|}
\hline & \multicolumn{2}{|c|}{$\begin{array}{l}\text { Mesma } \\
\text { etnia }\end{array}$} & \multicolumn{2}{|c|}{$\begin{array}{l}\text { Empre- } \\
\text { sários e } \\
\text { comer- } \\
\text { ciantes } \\
\text { locais }\end{array}$} & \multicolumn{2}{|c|}{$\begin{array}{l}\text { governo } \\
\text { local, } \\
\text { prefeitura, } \\
\text { câmara } \\
\text { vereadore } \\
\text { s }\end{array}$} & \multicolumn{2}{|c|}{$\begin{array}{l}\text { CONDE- } \\
\text { SUS }\end{array}$} & \multicolumn{2}{|c|}{$\begin{array}{l}\text { COREDE } \\
\text { Central }\end{array}$} & \multicolumn{2}{|c|}{$\begin{array}{c}\text { Sistema S } \\
\text { (SEBRAE, } \\
\text { SENAR, } \\
\text { SESC, } \\
\text { SENAI) }\end{array}$} & \multicolumn{2}{|c|}{$\begin{array}{c}\text { Universida } \\
\text {-des } \\
\text { (UFSM, } \\
\text { UNIFRA, } \\
\text { ULBRA) }\end{array}$} & \multicolumn{2}{|c|}{$\begin{array}{l}\text { Associaçõe } \\
\text { s, } \\
\text { sindicatos e } \\
\text { cooperativa } \\
\text { s }\end{array}$} & \multicolumn{2}{|c|}{$\begin{array}{l}\text { Turistas e } \\
\text { visitantes }\end{array}$} \\
\hline Var. & $\mathrm{N}$ & $\%$ & $\mathrm{~N}$ & $\%$ & $\mathrm{~N}$ & $\%$ & $\mathrm{~N}$ & $\%$ & $\mathrm{~N}$ & $\%$ & $\mathrm{~N}$ & $\%$ & $\mathrm{~N}$ & $\%$ & $\mathrm{~N}$ & $\%$ & $\mathrm{~N}$ & $\%$ \\
\hline 1 & 0 & $0 \%$ & 1 & $8 \%$ & 8 & $61 \%$ & 2 & $15 \%$ & & $8 \%$ & & $8 \%$ & 2 & $16 \%$ & 1 & $8 \%$ & 0 & $0 \%$ \\
\hline 2 & 0 & $0 \%$ & 1 & $8 \%$ & 0 & $0 \%$ & 1 & $8 \%$ & 2 & $15 \%$ & & $8 \%$ & 0 & $0 \%$ & 2 & $16 \%$ & 0 & $0 \%$ \\
\hline 3 & 1 & $8 \%$ & 7 & $54 \%$ & 3 & $23 \%$ & 3 & $23 \%$ & 3 & $23 \%$ & & $23 \%$ & 1 & $8 \%$ & 4 & $30 \%$ & 2 & $16 \%$ \\
\hline 4 & 1 & $8 \%$ & 4 & $30 \%$ & 2 & $16 \%$ & 1 & $8 \%$ & U & $0 \%$ & U & $46 \%$ & 6 & $46 \%$ & 4 & $30 \%$ & 5 & $38 \%$ \\
\hline 5 & 1 & $8 \%$ & 0 & $0 \%$ & 0 & $0 \%$ & 0 & $0 \%$ & 0 & $0 \%$ & 2 & $15 \%$ & 4 & $30 \%$ & 1 & $8 \%$ & 6 & $46 \%$ \\
\hline
\end{tabular}


RELACult - Revista Latino-Americana de Estudos em Cultura e Sociedade

\begin{tabular}{c|c|c|c|c|c|c|c|c|c|c|c|c|c|c|c|c|c|c}
6 & 0 & $0 \%$ & 0 & $0 \%$ & 0 & $0 \%$ & 3 & $23 \%$ & 4 & $31 \%$ & 0 & $0 \%$ & 0 & $0 \%$ & 0 & $0 \%$ & 0 & $0 \%$ \\
\hline 7 & 10 & $76 \%$ & 0 & $0 \%$ & 0 & $0 \%$ & 3 & $23 \%$ & 3 & $23 \%$ & 0 & $0 \%$ & 0 & $0 \%$ & 1 & $8 \%$ & 0 & $0 \%$ \\
\hline total & 13 & $\begin{array}{c}100 \\
\%\end{array}$ & 13 & $\begin{array}{c}100 \\
\%\end{array}$ & 13 & $\begin{array}{c}100 \\
\%\end{array}$ & 13 & $\begin{array}{c}100 \\
\%\end{array}$ & 13 & $100 \%$ & 13 & $100 \%$ & 13 & $100 \%$ & 13 & $100 \%$ & 13 & $\begin{array}{c}100 \\
\%\end{array}$ \\
\hline
\end{tabular}

Fonte: dados coletados na pesquisa de campo, no período de novembro de 2013 a abril de 2014.

Legenda: 1. Confia muito pouco; 2. Confia pouco; 3. Nem pouco, nem muito; 4. Confia muito; 5. Confia totalmente; 6. Desconheço; 7. Não influencia na confiança

Com relação ao item "mesma etnia" a maioria dos entrevistados, ou seja, $76 \%$ deles, atribuíram o conceito 7 (sete), afirmando que este é um fator que não influencia nas relações de confiança, apenas $8 \%$ respondeu 3 (três) "confia nem pouco e nem muito", $8 \%$ "confio muito" e 8\% "confio totalmente". Evidencia-se assim que a categoria "mesma etnia" não é um elemento que tem influência no fator de confiança entre os empresários locais.

Quanto à confiança que os pequenos empresários têm nos demais empresários e comerciantes locais 54\% assinalaram o conceito 3 (três), que confiam "nem pouco e nem muito", $30 \%$ "confia muito", $8 \%$ "confia pouco" e 8\% "confia muito pouco", o que demonstra desconfiança entre os próprios empresários, resultado este que contribui para a justificativa do baixo índice de capital social, porque este só é possível se tivermos a relação de confiança entre os agentes locais.

Para o grupo de governo local, prefeituras, câmara de vereadores, dos empresários entrevistados, $61 \%$ deles atribuíram o conceito 1 (um) "confia muito pouco", $23 \%$ "nem pouco e nem muito" e apenas 16\% "confia muito", indicando o baixo nível de confiança do empresariado local em seus gestores públicos, ou seja, falta de confiança no que Putman define como capital social formal, sendo também uma das causas que dificulta o trabalho coletivo entre o meio público e o setor privado.

Abu-el-Haj (1999) indica que a especificidade cultural é a chave para explicar o nível de capital social e o "predomínio do elemento cultural no grau de avanço do associativismo horizontal e a complementação de ações junto às instituições públicas” (ABU-EL-HAJ, 1999, p. 70). Já Evans e Fox $(1996,1992)$ rejeitam as conclusões culturalistas, afirmando que "as instituições públicas têm, além do monopólio da coerção, a exclusividade da mobilização dos recursos sociais" (ABU-EL-HAJ, 1999, p. 71). Sendo assim, a criação ou elevação do índice de capital social em determinados territórios dependeria da intervenção do Estado, já que, na sociedade moderna, ele é a arena principal da convergência das demandas sociais, determinando o sucesso das iniciativas voluntárias, tratando-se de um não enfático à visão de um determinismo cultural em matéria de mudança social, ou em termos de processo de desenvolvimento. 
Nas instituições do terceiro setor, as opiniões diversificam-se. Quando se trata do CONDESUS, há uma divisão variável de julgamentos: para 23\% "não influencia na confiança", $23 \%$ "desconhece", $23 \%$ "nem pouco e nem muito", $15 \%$ confia pouco e $8 \%$ confia muito pouco. Estes resultados, numa leitura geral, evidenciam a fragilidade das relações estabelecidas entre os empresários e o CONDESUS, que representa o consórcio dos municípios da Quarta Colônia, e, mais uma vez, reforça a recorrente afirmativa de dificuldades do trabalho coletivo entre setor público e privado.

A avaliação sobre o COREDE (Conselho Regional de Desenvolvimento) da região Central foi de que 31\% dos empresários entrevistados o "desconhecem", 23\% responderam que "não influencia na confiança", $23 \%$ confia "nem pouco e nem muito", $15 \%$ "confia pouco" e $8 \%$ "confia muito pouco", o que demonstra a inexpressiva relação entre os empresários e o COREDE.

O Sistema "S" foi avaliado de forma positiva pelos empresários, $46 \%$ deles atribuíram o conceito "confio muito", $23 \%$ "nem pouco e nem muito" e $15 \%$ "confia totalmente", e apenas $8 \%$ "confia pouco" e $8 \%$ "confia muito pouco". Considerando a relação de trabalhos já realizados e alguns que ainda seguem em parceria com o SEBRAE (Serviço Brasileiro de Apoio às Micro e Pequenas Empresas), entidade essa citada diversas vezes na fala dos entrevistados, o que demonstra um alto nível de confiança dos empresários no sistema "S".

O conjunto universidades obteve uma boa avaliação perante os empresários locais, $46 \%$ dos entrevistados atribuíram o conceito "confia muito", $30 \%$ "confia totalmente", 16\% "confio muito pouco" e 8\% "nem pouco, nem muito". Isso provavelmente ocorre devido ao trabalho que as faculdades têm no campo da pesquisa e da extensão e pelas parcerias em projetos na região.

Para as associações comerciais, sindicatos e cooperativas, os empresários atribuíram o conceito "confio muito" com $30 \%$, "nem pouco e nem muito" com $30 \%$, "confio pouco" com $16 \%$, "confio muito pouco" com $8 \%$, "confio totalmente com $8 \%$ e, por fim, "não influencia na confiança", também com $8 \%$. As notas foram bem divididas e atribui-se tal resultado a pouca e inexpressiva existência de associações na região, confirmada nas falas dos empresários quanto ao surgimento de associações que nunca funcionaram efetivamente, que não saíram do papel.

Por fim, questionou-se o grau de confiança dos entrevistados com relação aos turistas e visitantes em geral, e $46 \%$ dos empresários atribuíram o conceito "confio totalmente", 38\% “confio muito" e 16\% "nem pouco e nem muito" o que demonstra um alto grau de confiança 
nos turistas e visitantes, confirmando-se nas falas dos empresários que destacam as boas relações com os seus clientes, inclusive, com a existência de um visitante já freguês da casa.

Além de atribuir conceitos alguns dos entrevistados justificavam a sua opinião, assim, salientamos algumas das falas sobre os fatores de confiança ou de desconfiança dos empresários com relação aos atores e entidades questionadas. São elas:

Não confio totalmente nos comerciantes da região pela questão, assim, por exemplo, o vinho: tem um ou outro cliente que te pergunta de vinho colonial, mas esse ano é bom, amanhã não é bom, amanhã tá azedo. Então, não tem padrão. Então, nesse sentido, posso te dizer que a gente confia parcialmente. Olha, a gente se surpreende muito com os clientes, positivamente, eu confio muito nos meus clientes., com relação às cooperativas, já funcionou, mas hoje não funciona, por culpa da gente mesmo, não tem iniciativa. (Empresário AZ).

A gente já teve associações aqui que nunca funcionaram, eu participei de uma aqui, teve uma reunião ou duas e nunca mais teve nada, essas associações elas não duram muito, não se tem uma cultura de associativismo ainda, muito diferente de regiões aonde eu já participei em outras regiões. (Empresário DN).

Lembrando Fukuyama (1996), as pessoas que não confiam umas nas outras só irão cooperar num sistema de regras e regulamentos, que tem de ser negociado, acordado e posto em prática muitas vezes por meios coercivos, "a desconfiança generalizada no interior de uma sociedade impõe uma espécie de ônus sobre todas as formas de atividades econômicas, ônus que as sociedades de alto nível de confiança não têm de pagar” (1996, p. 43).

Os entrevistados foram questionados se, nos últimos cinco anos, o grau de confiança entre as pessoas da localidade melhorou, piorou ou se permaneceu o mesmo e, também, se as pessoas ajudam umas às outras. No grupo dos empresários, bem como para o representante do SEBRAE, o entendimento de ambos é de que não há confiança entre as pessoas da região nem busca de trocas mútuas. Nos depoimentos, aparecem elementos como: falta de espírito coletivo, não se relacionam com a comunidade, que as pessoas não colaboram porque elas têm "ciúmes", são individualistas, todos estes são aspectos que dificultam a constituição de capital social na região. Traz-se a afirmativa de Fukuyama (1996, p. 376): “... os seres humanos são ao mesmo tempo indivíduos mesquinhamente egoístas e criaturas com um lado social que evita o isolamento e aprecia o apoio e o reconhecimento de outros seres humanos".

As pessoas daqui não tem ambição pessoal. Se tem é acomodado. É legal numa festa de comunidade, todo mundo ajuda. Mas, fora isso, eu não vejo. (Empresário AZ).

A confiança continua a mesma coisa, a mesma relação que sempre teve, na verdade, a gente não se relaciona muito com a comunidade em si, até pela nossa atividade. Mas a gente se dá bem com todos os vizinhos, todo mundo sempre se dá. (Empresário BY). 
Não, não ajudam, se na hora de fazer uma festa de vez em quando pode ser, mas o pessoal é muito invejoso, a inveja tá em primeiro lugar, se tu for bem o pessoal já fica, se ajuda é muito pouquinho. (Empresário GT).

Acho que falta confiança, por exemplo, aqui assim, eu indico a Cascata do Mezzomo, aí os caras chegam lá e não deixam entrar. Chega lá e o cara não quer receber... Bem popularmente "ciúmes". (Empresário HS).

As pessoas são meio individualistas. Existe uma dificuldade de aderir as pessoas em associações, cooperativas, em trabalhar em grupo. (Empresário LO).

A nossa região não é uma região que tem uma necessidade financeira premente. Porque, se tivesse, trabalharia da forma que o nordeste tá trabalhando. Eu me junto contigo pra nós, juntas, ganhar mais dinheiro. Aqui na região, no sul, não! Rio Grande do Sul tem um poder econômico forte. E aí, eu me junto se eu vejo que eu tenho vantagens. É isso que tem que desaparecer. Eu tenho que perceber que eu tenho que me juntar para nós, todos, crescermos juntos. É uma questão cultural. (Político A - São João do Polêsine).

Na perspectiva de Putnam (1996), as associações civis contribuem para a eficácia e a estabilidade dos governos democráticos, em decorrência das externalidades positivas, produzidas sobre o indivíduo e sobre a sociedade. Quando os entrevistados sinalizam a dificuldade dos mesmos em organizarem-se em associações e cooperativas reforçam novamente a precariedade da constituição do capital social formal na região.

Os empresários foram questionados quanto à participação da empresa em algum projeto da comunidade. Dos treze empresários, apenas um relatou a realização de projetos desta característica, o que demonstra o baixo nível de ações de responsabilidade social e a integração entre o meio empresarial e a comunidade em geral.

A gente faz uma ação de educação ambiental, em algumas caminhadas se tem uma ação social, por exemplo, se faz um plantio de árvore, em cada um dos municípios, se designa um local, se planta uma muda de árvore nativa. Já se fez ações sociais pontuais, como a entrega de material escolar para 30 crianças de uma comunidade carente da Quarta Colônia. [...] em Faxinal houve uma enchente no ano passado e destruiu o local, onde tinha uma gruta que foi inaugurada em 2008 pelos peregrinos, mas a enchente levou e ficou o local atirado, então, agora, a gente fez essa ação, se plantou mudas de flores e plantas, os peregrinos plantaram lá, e um novo morador vai cuidar. (Empresário DN).

Estas ações de cunho social junto à comunidade relatadas apenas por um dos empresários são exemplos de cooperação mútua entre a agência de turismo receptivo e a comunidade, bem como entre os próprios turistas e a comunidade, que expressam valores de integração entre a iniciativa privada, comunidade e visitantes.

O desenvolvimento territorial do turismo pressupõe atores locais unidos por uma vontade solidária, de dinâmicas sociais endógenas, em que os próprios habitantes da comunidade conseguem potencializar os recursos e capacidades próprias. Para Putnam 
(1996), o capital social pode ser abordado em nível comunitário, onde certos grupos desenvolvem e mantêm mais ou menos capital social como um ativo coletivo; e como tal ativo pode melhorar a qualidade de vida dos membros da comunidade. Isto não exclui a possibilidade de que alguns grupos se beneficiem de tais vínculos sociais em detrimento de outros.

\section{Sessão de Alento - Nem tudo está perdido!}

O propósito desta sessão é demonstrar algumas ações relatadas pelos atores que são de cunho coletivo, tanto no cerne do setor público, quanto do privado e terceiro setor, que podem vir a representar a base para a constituição de uma rede sólida, possibilitando o fortalecimento do capital social da região.

Destacam-se alguns exemplos de ações coletivas no âmbito da comunidade a partir dos relatos dos gestores públicos, em especial, aquelas decorrentes nos eventos importantes, tais como o Dia do Vizinho, um acontecimento que é recorrente no calendário de eventos de muitos municípios da região, além de Dona Francisca, e também os tradicionais aniversários dos municípios, onde, na maioria das vezes, conta em sua programação com atividades organizadas pela comunidade local e gestores do governo local.

\footnotetext{
Julho tem o mês do vizinho, a gente mobiliza toda a comunidade, aquele dia é pra passar junto, é uma coisa bem interiorana, é uma integração, outro exemplo é a semana do município, a gente faz no dia do aniversário do município, toda a tarde as pessoas se juntam, um grupo vem e faz um risoto que é servido gratuitamente, ali tem a cultura de fazer, degustar, de como preparar, tirar aquele tempo pra viver em comunidade, tem várias outras ações, mas essa é especial. (Político $\mathrm{C}$ - Dona Francisca).
}

Muitas das ações voluntárias que acontecem na região têm sua origem nas tradições religiosas, onde as famílias contribuem de forma gratuita na constituição de comissões para organizar os festejos, almoços, jantares, bailes. Todavia, esses dois eventos acima citados não contemplam crenças e valores espirituais, são ações coletivas emanadas da vontade do conviver em comunidade.

Quanto às ações em rede dos atores privados, tem-se o exemplo do trabalho organizado pelo empresário DN, uma agência de viagens receptiva, o qual identificou como parceiros alguns empreendimentos de meios de hospedagem e alimentação e alguns grupos das comunidades locais, que são por ele escolhidos ao longo do trajeto das caminhadas. Isso dá-se pelo perfil do gestor e pela natureza da atividade de uma agência receptiva que, necessariamente, precisa estabelecer essas parcerias para formatar um produto turístico. 
Esse roteiro contempla 5 municípios, Silveira, Ivorá, São João do Polêsine, com Vale Vêneto junto e a sede de São João, Faxinal do Soturno, Nova Palma e agora entrou mais um, anos atrás, Júlio de Castilhos, devido ao Jardim das Esculturas [...] no primeiro dia um almoço em Guarda Mor e o pernoite em Vale Vêneto, o segundo dia um almoço na sede em Polêsine, no terceiro dia o jantar e o pernoite é em Novo Treviso, no salão comunitário, a gente tem uma estrutura de colchões e roupas de cama que é colocado lá para eles, eu tenho 20 colchões e a comunidade coloca os demais, eu contrato esse serviço do que falta, tudo é pago, não há trabalho voluntário [...] nessa última caminhada, tinha gente de até 10 estados do Brasil, da Paraíba, da Bahia. Então, essa é a terceira comunidade, no outro dia vão almoçar na Linha Três, que pertence a Nova Palma, é outra comunidade que há 14 anos trabalha com a gente, depois pernoitam no Jardim das Esculturas, é a quinta comunidade onde tem jantar e café da manhã, pernoite é familiar, eles dormem nas casas de família e tomam café da manhã lá, no meu entendimento é uma hospedagem de cama e café, depois, no último dia, eles almoçam na Linha Um e termina em Ivorá, com o café da colônia. Então são 8 comunidades rurais, aonde tem o serviço de hospedagem e alimentação. (Empresário DN).

Percebe-se o envolvimento da comunidade com os roteiros turísticos, neste caso, há uma pequena rede formada, onde todos ganham e têm o seu papel para exercer, são empresários, pessoas da comunidade em geral, que contribuem com o produto turístico de forma organizada e que expressam relações de confiança, credibilidade entre os atores envolvidos e benefícios mútuos. Foi um trabalho construído ao longo do seu percurso profissional, mais de 14 anos, onde o empresário relata avanços e retrocessos, mas que, de certa forma, mantém-se como um produto turístico organizado no coletivo, com laços de confiança e reciprocidade.

\section{Conclusões}

Os princípios do desenvolvimento territorial, com foco no turismo, são constituídos pela participação dos atores públicos e privados e do terceiro setor, por meio da formação de uma rede, atuando a partir de heranças culturais, políticas e econômicas, relações de confiança, em prol da valorização dos atributos do território. Ao longo desta pesquisa sobre o turismo na perspectiva do desenvolvimento territorial, o objetivo foi analisar em que medida os obstáculos que dificultam a realização do potencial e a consolidação do turismo no território que abrange a microrregião da Quarta Colônia, RS, Brasil, estão relacionados à noção de capital social.

Relaciona-se algumas das diversas iniciativas propostas pelos gestores municipais, associações, fóruns, consórcio e microempresários locais, demonstrando as limitações de cada uma quanto à organização de um trabalho coletivo, ou seja, a dificuldade de construir de forma grupal, permeadas muitas vezes pela desconfiança entre os atores. 
Para tanto, fez-se necessário investigar sobre a visão dos atores que estão envolvidos com o turismo na Quarta Colônia, identificando a existência ou não de formas de articulação coletivas a favor da atividade turística; identificar a recorrência ou não de laços de confiança e relações de cooperação entre os atores envolvidos.

Os processos de desenvolvimento podem aflorar mesmo quando há interesses divergentes entre os atores, cabendo à governança do território apontar os aspectos convergentes na construção de objetivos comuns, que possam gerar capacidade de associação e motivações de cunho coletivo entre eles, evidenciando os possíveis níveis de capital social existentes.

A iniciativa privada é essencial para que a atividade turística se desenvolva, sendo essa composta pelos atores que dinamizam com mais propriedade qualquer proposta de desenvolvimento em rede, como um APL de turismo. O perfil identificado pela amostra dos empreendimentos entrevistados é de pequeno porte, na sua maioria de gestão familiar, com destaque para os serviços turísticos de alimentação e meios de hospedagem, contemporâneos em sua maioria as iniciativas historiadas em prol do desenvolvimento turístico da microrregião. A maioria empresários naturais da microrregião ou da cidade de Santa Maria e tem vínculos familiares com a história da localidade, o que, de certa forma, enquadra na perspectiva do desenvolvimento territorial, de natureza endógena.

Entende-se que há carências de articulação e trabalho coletivo entre os representantes do setor empresarial. É preciso investir numa cultura de um empreendedorismo coletivo, para que se replique do empreendedorismo tradicional junto à comunidade regional em prol da diversificação da oferta de atrativos e serviços turísticos e, consequentemente, na ampliação do fluxo de visitantes e do tempo de permanência dos mesmos na microrregião. A visão dos empresários entrevistados foi demonstrada, em sua maioria, com traços individualistas, inexpressiva de ações associativas, revelando pouca densidade de capital social. Todavia, nas instâncias de gestão pública municipal e regional e do terceiro setor, foram identificadas algumas ações e estratégias de trabalho coletivo, que, mesmo com as suas limitações de articulação entre seus pares, apresentaram-se de forma mais organizada.

Quanto ao grau de confiança, os empresários, em sua maioria, não demonstram confiança nos governos municipais e são indiferentes quanto às instâncias de governança regionais, tais como CONDESUS, COREDE e associações comerciais, sindicatos e cooperativas, não confiando nem muito e nem pouco. Demonstraram um favorável grau de confiança nas instituições de ensino e no sistema " $\mathrm{S}$ " e também confiam nos visitantes e turistas que frequentam os seus estabelecimentos. Para o fortalecimento de forma positiva da 
densidade do capital social, será preciso investir em políticas e programas que favoreçam o estreitamento dos laços de confiança entre os agentes, lembrando que os empresários são os primeiros, no grau de relevância, para a constituição de um trabalho de desenvolvimento do turismo em rede, a exemplo da proposição que segue em pauta do APL de turismo.

A análise dos dados gerada ao longo deste trabalho deu origem a algumas contribuições, as quais foram organizadas em forma de sugestões, que podem ser úteis aos atores locais:

a) Definição de um plano estratégico para o turismo em nível da microrregião, construído de forma participativa e descentralizada, com a participação dos atores e que pode ser coordenada por uma instância de governança a ser instituída na região, como uma agência de desenvolvimento de turismo para a microrregião;

b) Criação de um comitê gestor para as ações do Turismo. Isso facilitaria a definição de estratégias comuns e a integração dos diversos atores envolvidos nos municípios. Também ajudaria na disseminação da informação e reforçaria os vínculos de confiança e cooperação.;

c) Definição de estratégias para melhorar as relações institucionais, as interações sociais entre os municípios, a fim de fortalecer a abordagem do Capital Social;

g) Aumento da participação da comunidade em geral no processo, estimulando a cultura empreendedora na microrregião e aproveitando o momento de investimento feito em prol do ensino superior de tecnologia em turismo no município de Silveira Martins (UDESSM);

Por fim, acredita-se que este trabalho possa servir de inspiração para novas abordagens a respeito do desenvolvimento do turismo em territórios rurais, atentos aos princípios do Capital Social e da abordagem em rede dos Arranjos Produtivos Locais.

\section{Referências}

ABRAMOVAY, R. O Futuro das regiões rurais. Porto Alegre: Editora da UFRGS, 2003.

ABRAMOVAY, R. Ruralidade e desenvolvimento territorial. Gazeta Mercantil, São Paulo, p. A-3, 15 abr. 2001.

ABU-EL-HAJ, J. O debate em torno do capital social: uma revisão crítica. Revista Brasileira de Informação Bibliográfica em Ciências Sociais - BIB, Rio de Janeiro, n. 47, p. 65-79, 1 sem. 1999.

ANÉSE, R. L. R. Arranjos produtivos locais e capital social no vale do Jaguari/RS. (Tese). Programa de Pós-Graduação em Economia da Faculdade de Ciências Econômicas da Universidade Federal do Rio Grande do Sul. Porto Alegre, 2009. 
BENI, M. C. Política e planejamento de turismo no Brasil. São Paulo: Aleph. 2006.

BOURDIEU, P. The forms of capital. In: RICHARDSON, J. (ed) Handbook of theory and research for the sociology of education. New York: Greenwood Press. 1985.

COLEMAN, J. S. Foundations of social theory. Cambridge MA: Haverd University Press. 1990.

CRUZ, R. de C. Política de turismo e território. São Paulo: Contexto. 2000.

FAVARETO, A. da S. Paradigmas do desenvolvimento rural em questão - do agrário ao territorial. Tese. Doutorado em Ciência Ambiental. FEA/USP. São Paulo. 2006.

FROEHLICH, J. M. Rural e Natureza - a construção social do rural contemporâneo na região central do Rio Grande do Sul. Tese (Doutorado em Ciências Sociais em Desenvolvimento, Agricultura e Sociedade). Rio de Janeiro: CPDA/UFRRJ, 2002.

FUKUYAMA, F. Confiança: as virtudes sociais e a criação da prosperidade. Tradução de Alberto Lopes. Rio de Janeiro: Rocco. 1996.

HAESBAERT, R. $O$ mito da desterritorialização: do "fim dos territórios" à multiterritorialidade. $2^{\text {a }}$ edição. Rio de Janeiro: Bertrand Brasil, 2006.

IDESTUR. Instituto de Desenvolvimento do Turismo. Conceitos Gerais de Turismo Rural. São Paulo. Disponível em: http://www.idestur.org.br/download/a_CONCEITO_GERAL_TURISMO_RURAL.pdf. Acesso em 17 de dezembro de 2014.

MINAYO, M. C. O desafio da pesquisa social. In: MINAYO, M. C. (Org). Pesquisa Social: teoria, método e criatividade. Petrópolis, RJ: Vozes. 1994.

MUELLER, A. A. Criação de novos municípios, capital social e desenvolvimento. (dissertação). Mestrado em Desenvolvimento Regional. Santa Cruz do Sul/RS, UNISC, 2007.

PUTNAM, R. D. Comunidade e democracia: a experiência da Itália moderna. $2^{\mathrm{a}}$ Ed. Rio de Janeiro: FGV. 2000.

SANTOS, M. Território e sociedade: entrevista com Milton Santos. São Paulo: Fundação Perseu Abramo, 2000.

TRIVIÑOS, A. N. S. Introdução à pesquisa em ciências sociais: a pesquisa qualitativa em educação. São Paulo: Altas, 1987.

WORDL BANK. Measuring social capital: an integrated questionnaire. Christiaan Grootaert ... [et al.]. p. cm. -- (World Bank Working Paper; no. 18), 2004. Disponível em: https://openknowledge.worldbank.org/bitstream/handle/10986/15033/281100PAPER0Measur ing0social0capital.pdf?sequence=1. Acesso em 22 de outubro de 2014. 